\title{
Preparation and evaluation of tacrolimus-loaded thermosensitive solid lipid nanoparticles for improved dermal distribution
}

This article was published in the following Dove Press journal: International Journal of Nanomedicine

\author{
Ji-Hyun Kang ${ }^{1} *$ \\ Jinmann Chon ${ }^{2, *}$ \\ Young-II Kim' \\ Hyo-Jung Lee' \\ Dong-Won $\mathrm{Oh}^{\prime}$ \\ Hong-Goo Lee' \\ Chang-Soo Han' \\ Dong-Wook Kim ${ }^{3}$ \\ Chun-Woong Park' \\ 'College of Pharmacy, Chungbuk \\ National University, Cheongju, Republic \\ of Korea; ${ }^{2}$ School of Medicine, Kyung \\ Hee University, Seoul, Republic of Korea; \\ ${ }^{3}$ Department of Pharmaceutical \\ Engineering, Cheongju University, \\ Cheongju, Republic of Korea \\ *These authors contributed equally to \\ this work
}

Background: Tacrolimus (TCR), also known as FK-506, is a biopharmaceutics classification system (BCS) class II drug that is insoluble in water because of its high log P values. After dermal application, TCR remains in the stratum corneum and passes through the skin layers with difficulty.

Purpose: The objectives of this study were to develop and evaluate solid lipid nanoparticles (SLNs) with thermosensitive properties to improve penetration and retention.

Methods: We prepared TCR-loaded thermosensitive solid lipid nanoparticles (TCR-SLNs) with different types of surfactants on the shell of the particle, which conferred the advantages of enhancing skin permeation and distribution. We also characterized them from a physic point of view and performed in vitro and in vivo evaluations.

Results: The TCR contained in the prepared TCR-SLN was in an amorphous state and entrapped in the particles with a high loading efficiency. The assessment of ex vivo skin penetration using excised rat dorsal skin showed that the TCR-SLNs penetrated to a deeper layer than the reference product $\left(0.1 \%\right.$ Protopic $\left.^{(}\right)$. In addition, the in vivo skin penetration test demonstrated that TCR-SLNs delivered more drug into deeper skin layers than the reference product. FT-IR images also confirmed drug distribution of TCR-SLNs into deeper layers of the skin.

Conclusion: These results revealed the potential application of thermosensitive SLNs for the delivery of difficult-to-permeate, poorly water-soluble drugs into deep skin layers.

Keywords: tacrolimus, thermosensitive, solid lipid nanoparticle, FT-IR imaging, atopic dermatitis, dermal delivery

\section{Introduction}

Correspondence: Chun-Woong Park College of Pharmacy, Chungbuk

National University, 194-21,

Osongsangmyeong I-ro, Heungdeok-gu,

Cheongju, Chungbuk 28160, Republic of Korea

Tel +82432613330

Fax +82432682732

Email cwpark@cbnu.ac.kr

Dong-Wook Kim

Department of Pharmaceutical

Engineering, Cheongju University, 298,

Deasung-ro, Cheongwon-gu, Cheongju,

Chungbuk 28503, Republic of Korea

Tel +82432297984

Fax +82432298577

Email pharmengin@cju.ac.kr
Tacrolimus (TCR) has shown notable therapeutic efficacy for immune-inflammatory conditions, including atopic dermatitis (AD). ${ }^{1}$ In 1999, TCR ointment, sold under the brand name Protopic ${ }^{\circledR}$ (Astellas Pharma, Japan), was approved by the US-FDA to treat moderate to severe cases of AD. TCR is a biopharmaceutics classification system (BCS) class II drug, with low solubility and high permeability. ${ }^{2}$ However, the physicochemical properties of TCR, namely its high molecular weight $(822.95 \mathrm{~g} / \mathrm{mol})$ and strong lipophilicity (partition coefficient $\log P=3.96 \pm 0.83$ ), indicate that it cannot readily pass through the skin barrier and penetrate into deeper skin layers. ${ }^{3}$ Previous research showed that when TCR was dermally applied, most of the drug did not penetrate the skin and remained in the stratum corneum. ${ }^{4} \mathrm{~A}$ new delivery system is therefore needed to allow greater penetration of TCR into the target areas, such as the 
epidermis and dermis, which are deeper in the skin than the stratum corneum. Currently, various delivery systems for TCR, such as polymeric micelle nanocarriers, ${ }^{5}$ solid lipid nanoparticles (SLNs), ${ }^{6}$ and nanosized lipid carriers ${ }^{7}$ are being actively studied. However, no reference products have yet been developed to overcome the drawback such as low solubility and strong lipophilicity.

SLNs were developed in the early 1990 s as an alternative drug delivery and carrier system to liposomes, emulsions, and polymeric nanoparticles. SLNs are produced by replacing the liquid lipid (oil) of an oil/water $(\mathrm{o} / \mathrm{w})$ emulsion with a solid lipid or a blend of solid lipids, such that the lipid particle matrix is solid at both room and body temperatures. ${ }^{8}$ SLN formulations for various application routes (parenteral, oral, transdermal, ocular, pulmonary, and rectal) have been developed and thoroughly characterized in vitro and in vivo. ${ }^{9,10}$ The incorporation of cosmetic and pharmaceutical actives has been demonstrated to be feasible. The mean particle size of SLNs is in the submicron range, from approximately 40 to $1000 \mathrm{~nm}$. SLNs combine the advantages of colloidal carriers and overcome some of their disadvantages. The SLN system offers many advantages for the target drug, such as the improved bioavailability of poorly water-soluble molecules or drugs. ${ }^{11}$ SLNs also have advantages such as sitespecific drug delivery, greater stability than liposomes, the ability to use biodegradable physiological lipids thereby decreasing the risk of acute and chronic toxicities, and the avoidance of organic solvents during production. ${ }^{12-14}$ SLNs have previously been developed with many advantageous characteristics for dermal and topical application. ${ }^{15,16}$ Their small size, of approximately $200 \mathrm{~nm}$ or less, ensures close contact with the stratum corneum and increased skin penetration of the drug. SLN formulations have been studied to determine their ability to improve the skin permeation of hydrophobic agents commonly used in cosmetics, such as coenzyme Q10, ${ }^{17}$ tocopherol (vitamin E), ${ }^{18}$ and retinol (vitamin A). ${ }^{19}$ The improved transdermal uptake of active compounds loaded into SLNs also result from an increase in the contact surface area between the active pharmaceutical ingredient and the corneocytes, a more rapid or extended release, and the use of surfactants as enhancers. $^{20}$

SLNs have been studied with classification of functional properties such as $\mathrm{pH}$ sensitive, thermosensitive, light responsive, and ultrasound responsive. Thermosensitive SLNs deposit or accumulate in the target sites through passive or active mechanisms, allowing efficient control of the distribution of the encapsulated active pharmaceutical ingredient (API) with a notable decrease in adverse events and drug wastage. Moreover, when SLNs reached the maximum accumulation in the target sites, sustained release of the encapsulated API occurred in response to changes in environmental factors, such as temperature. For example, many researchers have studied heat-sensitive nanoparticles that released drug only in heated lesions. ${ }^{21-23}$ High-intensity focused ultrasound (HIFU), used in cancer treatment, has also been applied. Several studies have investigated the release of drugs from thermosensitive nanoparticles as the temperature of cancer tissues is increased by HIFU. ${ }^{24-27}$ In addition, studies have been conducted to visualize the thermosensitive particles. Magnetic resonance imaging was used to track thermosensitive liposomes in vitro and in vivo. ${ }^{28-30}$ Indeed, it would be most desirable if the drugs could be efficiently administered in a manner that precisely matched the physiological needs at the proper sites and at proper times. ${ }^{31}$ In this study, as the temperature varied depending on the depth of the skin (for example, the stratum corneum contacting the outermost part of the skin is $30^{\circ} \mathrm{C}$ to $31^{\circ} \mathrm{C}$ and the temperature of the deep inner dermis is maintained at $36{ }^{\circ} \mathrm{C}$ to $-37^{\circ} \mathrm{C}$ ), the use of SLNs with thermosensitive properties has great potential to be an important novel drug delivery system. The objectives of this study were to develop and evaluate SLNs with thermosensitive properties to improve skin retention, and to visualize the improved penetration through ex vivo and in vivo experiments by using FT-IR imaging.

\section{Materials and methods Materials}

TCR was purchased from CKD Bio Corporation (Ansan, Korea). Cocoglyceride was obtained from BASF (Ludwigshafen, Germany). The reference product was $0.1 \%$ Protopic $^{\circledR}$ ointment (Astellas Pharm, Tokyo, Japan). Stearic acid was purchased from Tokyo Chemical Industry Co. Ltd (Tokyo, Japan). Poloxamer 188 was supplied by Croda International (Snaith, UK), and soybean lecithin was purchased from Samchun Chemical (Pyeongtaek, Korea). Brij ${ }^{\circledR} 93$ and Brij $^{\circledR} 58$ were purchased from Sigma Aldrich Corporation (St. Louis, USA). Methylene chloride was purchased from OCI Corporation (Seoul, Korea). High-performance liquid chromatography (HPLC) grade ethanol and acetonitrile were purchased from Honeywell Burdick \& Jackson (Muskegon, USA). Water was purified by filtration in the laboratory. HPLC- 
grade solvents were used for the analysis. Sprague Dawley ${ }^{\circledR}$ Rats and New Zealand white rabbits were purchased from Samtako Corporation (Osan, Korea).

\section{Methods}

\section{Preparation of SLNs}

TCR-SLNs were prepared by using a modified method of previously studied emulsification and low temperature solidification. ${ }^{32}$ The drug-oil and lipid phases were separately prepared. The drug-oil phase and lipid phase was mixed at $5,000 \mathrm{rpm}$ and $50{ }^{\circ} \mathrm{C}$ for $20 \mathrm{~min}$ using a homogenizer. The drug-oil-lipid phase was injected slowly into an aqueous phase at $70{ }^{\circ} \mathrm{C}$ over $15 \mathrm{~min}$, and then mixed at $15,000 \mathrm{rpm}$ and $70{ }^{\circ} \mathrm{C}$ for $20 \mathrm{~min}$ using a homogenizer. The mixture was rapidly poured into an ice-water in chiller (RW-0525G, Jeiotech ${ }^{\circledR}$, Daejeon, Korea) at $0{ }^{\circ} \mathrm{C}$ to form the TCR-SLN emulsion. The mixture was sonicated in the chiller at $0{ }^{\circ} \mathrm{C}$ by using a probe sonicator (VP-5S, Taitec ${ }^{\circledR}$ Corporation, Koshigaya, Japan) to obtain a stable TCR-SLN suspension. The blank SLN suspension was obtained by using the same method in the absence of TCR when preparing the drug-oil-lipid phase (Table 1). The composition of each TCR-SLN is described in Table 2, and the method of preparing each phase is briefly described. The drug-oil phase was obtained by accurately weighing cocoglyceride and TCR and dissolving them in methylene chloride. Soybean lecithin and Brij ${ }^{\circledR} 93$ were dissolved in ethanol by using a homogenizer (T-18, IKA ${ }^{\circledR}$, Staufen, Germany) at $5,000 \mathrm{rpm}$ and $50{ }^{\circ} \mathrm{C}$ for $20 \mathrm{~min}$ to the obtain the lipid phase. The aqueous phase comprised $2 \%(\mathrm{w} / \mathrm{v})$ surfactant in distilled water.

\section{Physicochemical characterization of TCR-SLNs}

\section{Particle size distribution and entrapment efficiency}

The particle size and polydispersity index were detected by using a zeta-size analyzer (Portal ELSZ size analyzer, Otsuka ${ }^{\circledR}$ Electronics, Osaka, Japan). Measurements were performed at an angle of $90^{\circ}$ and a temperature of $25^{\circ} \mathrm{C}$. One milliliter of TCR-SLN suspension was added to the cuvette and the particle size was measured. Each experiment was conducted three times.

The prepared TCR-SLNs ( $500 \mu \mathrm{L})$ were filtered through an Amicon $^{\circledR}$ Ultrafilter $10 \mathrm{kDa}$ (Merck Millipore, Burlington, USA) and centrifuged (MEGA17R, Hanil Science Medical, Daejeon, Korea) at $17,500 \mathrm{rpm}$ and $4{ }^{\circ} \mathrm{C}$ for $50 \mathrm{~min}$. The filtered solution was diluted 10 times with the mobile phase and TCR was quantified using HPLC. The column properties were: $5 \mu \mathrm{m}, \mathrm{C} 18100 \AA, 150 \times 4.6 \mathrm{~mm}$ (Youngjin Biochrom Co., Ltd, Seongnam, Korea). The

Table I Formulations of blank-SLNs

\begin{tabular}{|c|c|c|c|c|c|c|}
\hline & Excipient & SLN-B I & SLN-B2 & SLN-B3 & SLN-B4 & Solvent \\
\hline Oil phase & Cocoglyceride & $0.4 \mathrm{~g}$ & $0.4 \mathrm{~g}$ & $0.4 \mathrm{~g}$ & $0.4 \mathrm{~g}$ & Methylene chloride \\
\hline Lipid phase & $\begin{array}{l}\text { Lecithin } \\
\text { Brij }^{\circledR} 93\end{array}$ & $\begin{array}{l}0.3 \mathrm{~g} \\
1.0 \mathrm{~g}\end{array}$ & $\begin{array}{l}0.3 \mathrm{~g} \\
1.0 \mathrm{~g}\end{array}$ & $\begin{array}{l}0.3 \mathrm{~g} \\
1.0 \mathrm{~g}\end{array}$ & $\begin{array}{l}0.3 \mathrm{~g} \\
1.0 \mathrm{~g}\end{array}$ & Ethanol \\
\hline Aqueous phase & $\begin{array}{l}\text { Poloxamer } 188 \\
\text { PEG-40 stearate } \\
\text { Brij }^{\circledR} 58 \\
\text { PEG-1000 }\end{array}$ & $\begin{array}{l}1.0 \mathrm{~g} \\
- \\
- \\
-\end{array}$ & $\begin{array}{l}- \\
1.0 \mathrm{~g} \\
- \\
-\end{array}$ & $\begin{array}{l}- \\
- \\
1.0 \mathrm{~g} \\
-\end{array}$ & $\begin{array}{l}- \\
- \\
- \\
1.0 \mathrm{~g}\end{array}$ & Distilled water \\
\hline
\end{tabular}

Table 2 Formulations of TCR-SLNs

\begin{tabular}{|c|c|c|c|c|}
\hline & Excipient & TCR-SLN-I & TCR-SLN-2 & Solvent \\
\hline Drug-oil phase & $\begin{array}{l}\text { Coco glyceride } \\
\text { Tacrolimus }\end{array}$ & $\begin{array}{l}0.4 \mathrm{~g} \\
0.1 \mathrm{~g}\end{array}$ & $\begin{array}{l}0.4 \mathrm{~g} \\
0.1 \mathrm{~g}\end{array}$ & Methylene chloride \\
\hline Lipid phase & $\begin{array}{l}\text { Lecithin } \\
\text { Brij }^{\circledR} 93\end{array}$ & $\begin{array}{l}0.3 \mathrm{~g} \\
1.0 \mathrm{~g}\end{array}$ & $\begin{array}{l}0.3 \mathrm{~g} \\
1.0 \mathrm{~g}\end{array}$ & Ethanol \\
\hline Aqueous phase & $\begin{array}{l}\text { Poloxamer } 188 \\
\text { Briij }^{\circledR} 58\end{array}$ & $\begin{array}{l}1.0 \mathrm{~g} \\
-\end{array}$ & $\begin{array}{l}- \\
1.0 \mathrm{~g}\end{array}$ & Distilled water \\
\hline
\end{tabular}


mobile phase was a mixture of acetonitrile and distilled water solution $(70: 30 \mathrm{v} / \mathrm{v})$, which was filtered through a $0.2 \mu \mathrm{m}$ membrane filter (Sartorius, Gottingen, Germany) and then degassed before use. The mobile phase was pumped at a flow rate of $1.1 \mathrm{~mL} / \mathrm{min}$. The column temperature was set at $50{ }^{\circ} \mathrm{C}$, and the detection wavelength was set at $210 \mathrm{~nm}$.

The entrapment efficiency was calculated from the following equation

Entrapment efficiency $(\%)=\frac{C_{\text {initial drug }}-C_{\text {free drug }}}{C_{\text {initial drug }}} \times 100$

Where $C_{\text {initial drug }}$ is the concentration of the initial TCRSLN suspension used for the preparation of TCR-SLN and $C_{\text {free drug }}$ is the concentration of free TCR detected in the residual solution after centrifugation.

\section{Differential scanning calorimetry}

The thermal properties of the TCR raw material, other excipients, blank-SLNs, and prepared TCR-SLNs were analyzed by using a DSC Q2000 (TA Instruments, New Castle, USA) thermal analyzer system. Blank-SLNs and prepared TCRSLNs were lyophilized by using a FreeZone 2.5 L Benchtop Freeze Dry System (LABCONCO ${ }^{\circledR}$, Kansas City, USA), which removed all water to leave a dry powder. The samples were accurately weighed, loaded into an aluminum pan, and analyzed at a heating rate of $10{ }^{\circ} \mathrm{C} / \mathrm{min}$ over a temperature range of $20{ }^{\circ} \mathrm{C}$ to $200{ }^{\circ} \mathrm{C}$. The thermal response of the prepared sample was calculated by using TA Advantage/ Universal Analysis software (v5.2.6). The crystallinity of the prepared TCR-SLNs was determined from the enthalpy of Tm in the DSC.

\section{$X$-ray diffraction}

X-ray diffraction (XRD) patterns of the TCR raw material, other excipients, physical mixture, and lyophilized TCRSLNs were analyzed by using the D8 Discover with GADDS (Bruker AXS, Karlsruhe, Germany) at a wavelength of $1.54 \AA$. The $2 \theta$ scans were conducted between $5^{\circ}$ and $60^{\circ}$.

\section{Fourier-transform infrared spectroscopy}

Infrared spectroscopy was performed by using a Fourier transform infrared (FT-IR) spectrophotometer (4100 Jasco Tokyo, Japan). For each spectrum, 16 transient spectra were collected over the range $650-4000 \mathrm{~cm}^{-1}$ for the $\mathrm{TCR}$, Brij ${ }^{\circledR} 58$, Poloxamer 188 , the physical mixture, and the prepared TCR-SLNs.

\section{Transmission electron microscopy}

Transmission electron microscopy (TEM) was used to visualize the morphology and structure of the prepared TCR-SLNs. First, the copper grid (TED PELLA Corporation, Redding, USA) was soaked in a drop of TCR-SLN suspension for $1 \mathrm{~min}$. Subsequently, the particles on the grid were dyed with $2 \%(\mathrm{w} / \mathrm{v})$ phosphotungstic acid solution for $10 \mathrm{~s}$ and washed twice with distilled water for $1 \mathrm{~s}$. The grids were dried for approximately $30 \mathrm{~min}$ at temperatures of $25^{\circ} \mathrm{C}, 37^{\circ} \mathrm{C}$, and $50{ }^{\circ} \mathrm{C}$. The images of prepared particles were captured by using LIBRA 120 (Carl Zeiss, Oberkochen, Germany) with an accelerating voltage of $200 \mathrm{kV}$.

\section{In vitro/ex vivo evaluation of TCR-SLNs}

\section{In vitro release test of TCR-SLNs}

In vitro release studies were performed by using $12 \mathrm{~mL}$ Franz-diffusion cells (16 $\mathrm{mm}$ in diameter). The Franz-diffusion cell was regulated at $37^{\circ} \mathrm{C}$ by using a water jacket and the Franz-box was maintained at $32{ }^{\circ} \mathrm{C}$. Dialysis membrane (Spectra/Por $^{\circledR} 2$ dialysis membrane standard RC sheets, Repligen Corporation, Waltham, USA) with a molecular weight cut-off (MWCO) of 12-14 kDa and a pore size of $2.4 \mathrm{~nm}$ were used for the release experiments. Ethanol and pH 7.4 phosphate buffer solution (PBS) were mixed in a 3:7 $(\mathrm{v} / \mathrm{v})$ ratio and used as the receptor phase. A $500 \mu \mathrm{L}$ aliquot of the prepared TCR-SLNs $(0.1 \%$ TCR) was applied to the donor compartment and covered with Parafilm ${ }^{\circledR}$ to prevent drying. The concentration of TCR in the samples from receptor fluid was analyzed by using HPLC.

\section{Ex vivo skin penetration test of TCR-SLNs}

The ex vivo skin penetration test of TCR-SLNs was conducted by using excised rat dorsal skin samples from 8week-old Sprague Dawley rats. The skins were hydrated with PBS and then mounted in the Franz-diffusion cell. The $\mathrm{pH} 7.4$ PBS containing ethanol $(30 \% \mathrm{v} / \mathrm{v})$ was used as the receptor fluid. The dorsal skin was in full contact with the receptor phase. A $500 \mu \mathrm{L}$ aliquot of the prepared TCRSLNs $(0.1 \% \mathrm{w} / \mathrm{w}$ TCR) and $500 \mathrm{mg}$ of the reference product were applied to the donor compartment and covered with Parafilm ${ }^{\circledR}$ to prevent drying. Ex vivo skin penetration was examined over a $24 \mathrm{~h}$ period. The stratum corneum was separated by using adhesive tape (3M Scotch $^{\circledR}$ ) and the dermis/epidermis was cut into six pieces. ${ }^{33}$ Each piece was placed in a $15 \mathrm{~mL}$ conical tube with $5 \mathrm{~mL}$ of mobile phase and sonicated to extract the TCR. Subsequently, the solution was filtered through a 
$0.45 \mu \mathrm{m}$ pore syringe filter (Whatman ${ }^{\mathrm{TM}} 25 \mathrm{~mm} \mathrm{GD} / \mathrm{X}$ syringe filter, Whatman ${ }^{\circledR}$, Maidstone, UK) and diluted with mobile phase in a 1:1 ratio. The exact concentration of TCR in each skin tested was quantified by using HPLC.

FT-IR imaging was performed to determine the distribution of TCR throughout the depth of the skin. After the ex vivo skin penetration test for $24 \mathrm{~h}$, the skin was cut into $50 \mu \mathrm{m}$ slices from top to bottom by using a cryomicrotome (Microm HM450, Thermo Scientific, Waltham, USA). Up to approximately $900 \mu \mathrm{m}$ of the skin was obtained and cut vertically to determine the difference in TCR by depth. The skin slice was placed on a glass slide (Marinefield Superior, Lauda-Königshofen, Germany) and examined by FT-IR imaging (Cary 670 \& Cary 620, Agilent $^{\circledR}$ Technologies, Santa Clara, USA). In each experiment, the wavelength of $3450 \mathrm{~cm}^{-1}$ was used for analysis. Each IR field of view size was a square with sides of $352 \mu \mathrm{m}$ and each IR pixel was a square with sides of $5.5 \mu \mathrm{m}$. In the FT-IR images, a red color indicated a relatively high concentration of TCR, whereas a blue color indicated a relatively low amount of TCR.

\section{In vivo skin penetration of TCR-SLNs}

The in vivo skin penetration test was performed by using a modified method described previously. ${ }^{34}$ The hair on the dorsal skin of New Zealand white rabbits was shaved before the test compounds were applied to an $8 \times 6 \mathrm{~cm}^{2}$ area. The TCR-SLNs and reference product were each applied to five rabbits once daily for 2 weeks on the shaved skin. At $24 \mathrm{~h}$ after the last application, the rabbits were sacrificed. Any remaining drug on the area was removed with a cotton swab, and the skin was excised. A $50 \mu \mathrm{m}$ slice was prepared using the same methods used for the FT-IR imaging. The residual amount of TCR in the horizontal section was analyzed by HPLC and FT-IR imaging.

Skin irritation in rabbits was evaluated by using the Draize test. The appearance of erythema was evaluated at $24 \mathrm{~h}$ after the final application. The dorsal skin was graded (Table 3) from no erythema (score: 0 ) to severe erythema (score: 4$)^{35}$ and the images of skin were scored by nine blinded observers.

Table 3 Grading scale for the Draize test

\begin{tabular}{|l|l|}
\hline Grade & Formation of erythema \\
\hline 0 & No erythema \\
1 & Very slight erythema \\
2 & Well-defined erythema \\
3 & Moderate to severe erythema \\
4 & Severe erythema \\
\hline
\end{tabular}

All animal experiments were conducted in accordance with the "Principles of Laboratory Animal Care" and approved by the Committee for Animal Experiments of Chungbuk National University (Cheongju, Korea).

\section{Statistics}

All statistical analyses were computed by using SPSS version 23 (SPSS Inc., IL, USA). Differences were determined using the Student's $t$-test with significance set at $p$ values of less than 0.05 .

\section{Results and discussion Characterization of SLNs Preparation of TCR-SLNs}

Previous studies have shown that the elution pattern of SLNs was dependent on the lipids comprising the SLN. ${ }^{36}$ Surfactants that form the shell of the particles were screened to obtain SLN with the desired thermosensitive properties. Poloxamer 188, PEG-40 stearate, Brij ${ }^{\circledR}$ 58, and PEG-1000 were chosen for the shell surfactant of thermosensitive SLNs (Table 1). The DSC profiles of the surfactant raw materials and SLN-Bs prepared with each surfactant are shown in Figure 1(A). The DSC profiles showed that the endothermic peak temperature of the prepared SLNs was generally relatively lower than that of the raw surfactant materials. The $\mathrm{T}_{\mathrm{m}}$ of PEG- 1000 was $31{ }^{\circ} \mathrm{C}$ and the $\mathrm{T}_{\mathrm{m}}$ of SLN-B4 was $27^{\circ} \mathrm{C}$. This was too low for SLNs with PEG1000 to remain stable at room temperature. The particles were relatively easily degraded and did not maintain their shape. For Brij ${ }^{\circledR} 58$, which has a $\mathrm{T}_{\mathrm{m}}$ of $38{ }^{\circ} \mathrm{C}$, the $\mathrm{T}_{\mathrm{m}}$ of SLN-B3 was $33{ }^{\circ} \mathrm{C}$; this was the closest to body temperature. In contrast, the $\mathrm{T}_{\mathrm{m}}$ of PEG-40 and Poloxamer 188 was approximately $50{ }^{\circ} \mathrm{C}$ and $60^{\circ} \mathrm{C}$, respectively; SLN-B1 and SLN-B2 displayed endothermic peaks at $48{ }^{\circ} \mathrm{C}$ and $46{ }^{\circ} \mathrm{C}$. SLN-B1, which contained Poloxamer 188, had the highest $\mathrm{T}_{\mathrm{m}}$ of the prepared blank-SLNs. Two candidate surfactants, Poloxamer 188 and Brij ${ }^{\circledR}$ 58, were selected, and SLNs made from these surfactants were examined for their physicochemical properties and subjected to in vitro/ex vivo testing. The final formulation that was chosen for further study is shown in Table 2. In the prepared TCR-SLN groups, the TCR content was $0.1 \% \mathrm{w} / \mathrm{w}$, which was the same as that of reference product.

\section{Physicochemical properties of TCR-SLNs}

As shown in Table 4, the two prepared SLNs containing TCR had a mean particle size of $152.9 \pm 4.09 \mathrm{~nm}$ and 143.1 $\pm 7.98 \mathrm{~nm}$, respectively, and PDI values of $0.25 \pm 0.03$ and 

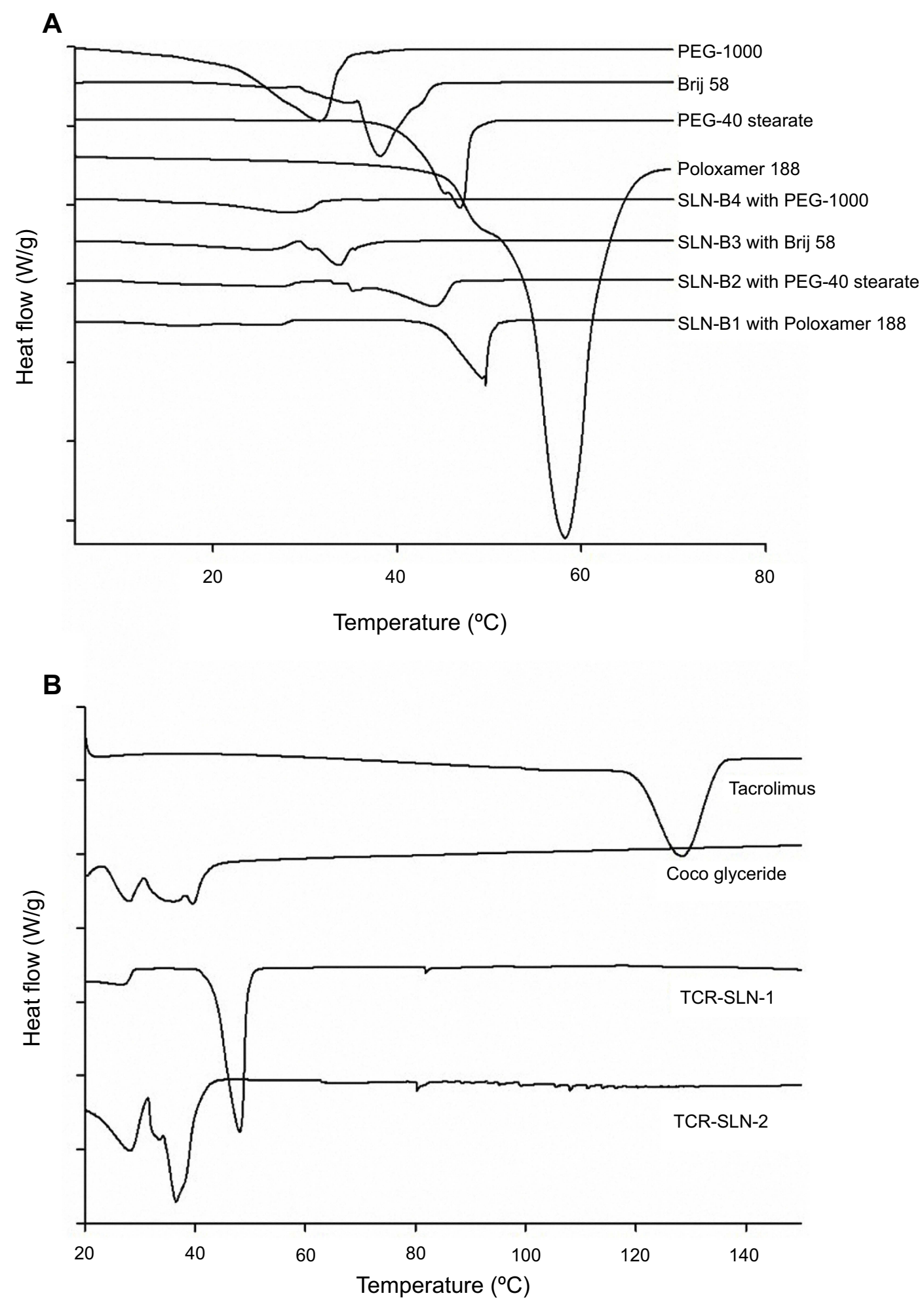

Figure I DSC thermograms of: (A) the raw surfactant and blank SLNs prepared with surfactant; (B) the raw materials and prepared TCR-SLNs.

$0.27 \pm 0.02$, respectively; despite the different surfactants, these values were not significantly different. These results showed that when the particles were manufactured in accordance with the indicated preparation method, ${ }^{37}$ small and uniform particles of approximately $150 \mathrm{~nm}$ were produced.

The drug entrapment efficiency is an important index to determine whether the prepared SLNs meet clinical 
Table 4 Particle properties of TCR-SLNs (mean \pm standard deviation)

\begin{tabular}{|l|l|l|}
\hline & TCR-SLN-I & TCR-SLN-2 \\
\hline Mean particle size (nm) & $152.9 \pm 4.09$ & $143.1 \pm 7.98$ \\
Polydispersity index & $0.25 \pm 0.03$ & $0.27 \pm 0.02$ \\
Entrapment efficiency (\%) & $88.9 \pm 0.7$ & $88.5 \pm 0.2$ \\
\hline
\end{tabular}

requirements and to judge their suitability as a drug carrier system. The term entrapment implies that the drug is positioned within the solid lipid matrix. As shown in Table 4, the entrapment efficient of TCR-SLN-1 and TCR-SLN- 2 was $88.9 \% \pm 0.7 \%$ and $88.5 \% \pm 0.2 \%$, respectively. The entrapment standard deviation was also low, indicating uniform entrapment. These results suggested that TCR is more abundant in the lipid phase (SLN) than in the aqueous phase, a result of the physicochemical properties of TCR such as high hydrophobicity, low solubility in water, and high $\log P^{38-40}$

The DSC thermograms of raw TCR, cocoglyceride, and TCR-SLNs are shown in Figure 1(B). The breakdown of the crystalline lattice by heating, information about the lipid structure, and the possibility of polymorphisms, crystal ordering, or glass transition processes can be easily detected by DSC. The DSC thermogram of raw TCR showed one endothermic peak with an onset temperature at $128{ }^{\circ} \mathrm{C}$, which was indicative of melting and the crystalline nature of the raw TCR; this also confirmed the XRD results. The thermogram of cocoglyceride showed a widened and split endothermic peak from $25{ }^{\circ} \mathrm{C}$ to $40{ }^{\circ} \mathrm{C}$. The thermograms of prepared TCR-SLN-1 and TCR-SLN-2, made with Poloxamer 188 and Brij $^{\circledR} 58$ respectively, were most affected by the presence of surfactant. In addition, no TCR-SLNs exhibited characteristic TCR endothermic melting peaks, indicating that the TCR exists in an amorphous state within the TCR-SLNs. TCR-SLN-1 showed an endothermic peak at $48{ }^{\circ} \mathrm{C}$, thought to be derived from Poloxamer 188 , and an endothermic peak at approximately $28{ }^{\circ} \mathrm{C}$ from cocoglyceride. This was similar to B-SLN-1. TCRSLN-2 showed endothermic peaks at $28{ }^{\circ} \mathrm{C}$ and $36{ }^{\circ} \mathrm{C}$ and endothermic peaks at higher temperatures than BSLN-3 but formed at lower temperatures than the $T_{m}$ of Brij $^{\circledR}$ 58. Overall, an endothermic peak at approximately $28{ }^{\circ} \mathrm{C}$, which is derived from cocoglyceride, was common in the TCR-SLNs. In addition, the main endothermic peak of TCR-SLNs shifted to a lower temperature compared with that of the raw surfactant. A reduction in the
$\mathrm{T}_{\mathrm{m}}$ and enthalpy of the melting endotherm was observed when the lipid was formulated as TCR-SLNs. ${ }^{41}$ Freitas and Muller also observed that the crystallization behavior of SLNs differed distinctly from that of the raw lipid. ${ }^{42}$ The small particle size of SLNs results in a high surface energy, which creates an energetically suboptimal state that results in a decrease in the melting point. ${ }^{43}$

The XRD data shown in Figure 2 agreed well with the results from DSC. Powder XRD analysis offers the clear advantage of allowing the identification of the crystalline or amorphous state of lipid particles and their crystal modification. Raw TCR exhibited sharp and narrow diffraction peaks at $2 \theta$ of $5^{\circ}-30^{\circ}$, which are characteristic of a high degree of long-range molecular order. Moreover, Poloxamer 188 and $\mathrm{Brij}^{\circledR} 58$ showed two peaks at $2 \theta$ of $19^{\circ}$ and $23^{\circ}$, and the two peaks of the surfactant contained in TCR-SLNs were weak. Furthermore, the diffraction pattern of the prepared TCR-SLNs differed considerably from that of raw TCR. The peaks of raw TCR mostly disappeared in the XRD pattern of TCR-SLNs, indicating that the crystal arrangement in the SLN formulations was less ordered than that in raw TCR. The loss of crystallinity in the XRD pattern of the lyophilized SLN was discerned through the absence of sharp peaks and the loss of most of the peaks of TCR. ${ }^{44}$ Through comparison with earlier results, it was concluded that the drug entrapped in the prepared TCR-SLNs was in an amorphous or disordered crystalline phase of a molecular dispersion. The amorphous form is thought to have higher energy with a greater surface area and, subsequently, higher solubility, dissolution rates, and bioavailability. ${ }^{45}$ These properties of the amorphous form are expected to facilitate overcoming

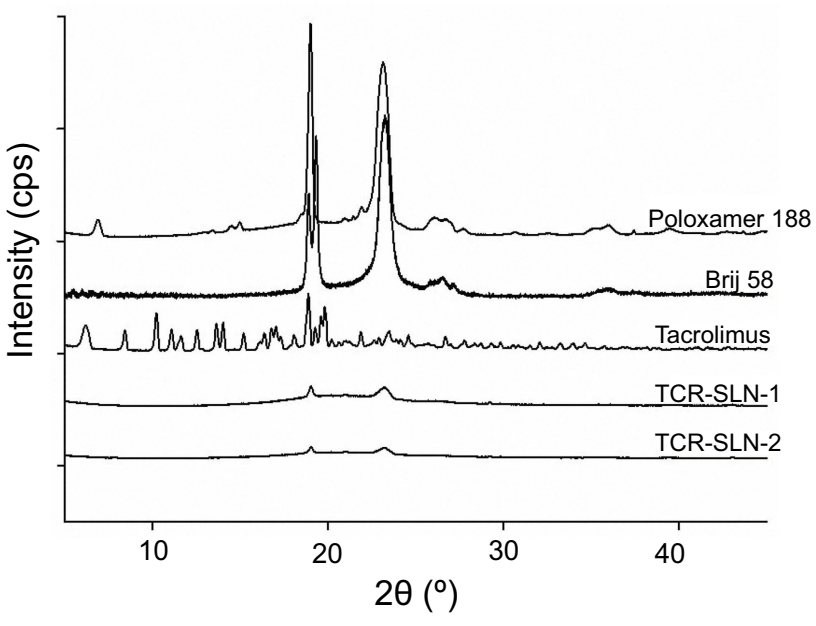

Figure $2 \times R D$ patterns of the raw materials and prepared TCR-SLNs. 
skin permeability barriers and conferring a significant improvement in bioavailability after absorption.

FT-IR analysis can provide further confirmation of the stability and crystallinity of prepared TCR-SLNs. In this study, raw TCR, Poloxamer 188, Brij ${ }^{\circledR} 58$, prepared TCRSLN-1 and -2 , and physical mixtures of the TCR-SLN-1 and -2 composition were analyzed and the FT-IR spectra obtained were used as references for the evaluation of the lipid lattice structures of the prepared TCR-SLNs. The FTIR spectra are shown in Figure 3. The spectrum of raw TCR was similar to previous studies that showed strong infrared absorption at 3446, 2935, and $1639 \mathrm{~cm}^{-1}$.,46 These peaks correspond to $\mathrm{O}-\mathrm{H}$ stretching, alkane $\mathrm{C}-\mathrm{H}$ bonds, and the $\mathrm{C}=\mathrm{O}$ bond of the carbonyl ester group. ${ }^{47,48}$ The peaks of raw TCR were weak, but present in the physical mixture; however, the peaks of the prepared TCR-SLN-1 and -2 were shifted more and were wider than for the physical mixture. This result was likely attributable to the complete encapsulation of TCR, its interaction with the excipients, and the change in crystallinity. ${ }^{49}$ These results agreed with the observations made by Lee et al during their study on encapsulation in SLNs ${ }^{50}$ As the peaks at $3450 \mathrm{~cm}^{-1}$ do not overlap peaks with other excipients and are more intense than the physical mixture, we used this as the wavelength for detection of FT-IR images and subsequent experiments (Figure 3).

TEM imaging can be used to directly identify the morphology of the prepared nanoparticles. The shape of the nanoparticles prepared with TCR is shown in Figure 4. The particles displayed round and homogenous shading, with a particle size of approximately $150 \mathrm{~nm}$. This clearly supported the data for the particle size and polydispersity index values. The TCR-SLNs were surrounded by the hydrophilic Poloxamer aqueous solution owing to the previously described interfacial phenomenon. ${ }^{51,52}$ The

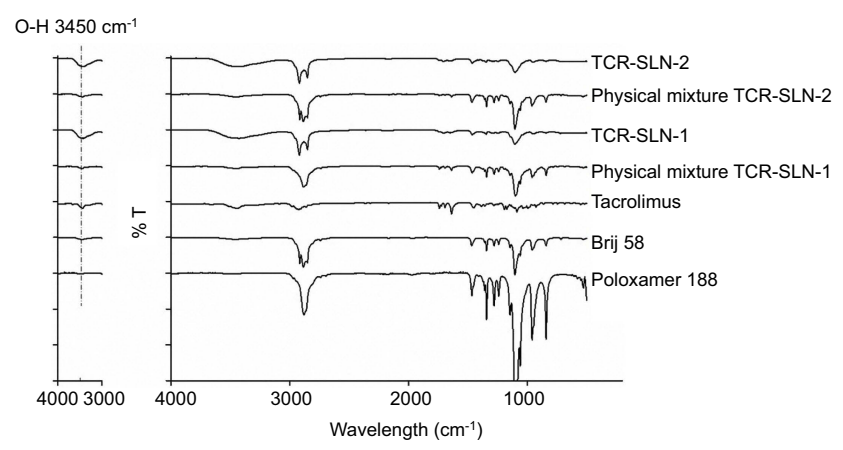

Figure 3 FT-IR spectra of the raw materials, prepared TCR-SLNs, and physical mixtures of TCR-SLN materials. excellent stability is a result of the adequate surfactant content, including Poloxamer $188 .^{53,54}$ The TEM images obtained by drying at three different temperatures $\left(25^{\circ} \mathrm{C}\right.$, $37^{\circ} \mathrm{C}$, and $50{ }^{\circ} \mathrm{C}$ ) are shown in Figure 4 , and reveal the characteristics of the particles produced at different temperatures. For the TCR-SLN-1 particles dried at $37{ }^{\circ} \mathrm{C}$ (Figure 4(c)), the outer shape of the Poloxamer 188 maintained the structure well, but the particles became blurry and round and was slightly larger than that of particles dried at $25^{\circ} \mathrm{C}$. It appears that cocoglyceride changed from a solid to a liquid form, as indicated by the endothermic peak at approximately $28{ }^{\circ} \mathrm{C}$ in the DSC thermogram of TCRSLNs. This is the reason for the extensibility of the molten SLNs. ${ }^{55}$ Moreover, when the temperature of the particles was increased to $50^{\circ} \mathrm{C}$ (Figure 4(e)), most did not maintain their shape and coagulated with other particles; alternatively, all the particles melted and did not maintain their shape. However, when TCR-SLN-2 was observed at these temperatures, a difference in particle shape was already visible at approximately $37^{\circ} \mathrm{C}$ (Figure 4(D)). When dried at $37{ }^{\circ} \mathrm{C}$, the shape of most of the particles was not maintained owing to the presence of Brij ${ }^{\circledR} 58$ in TCR-SLN-2, and the size of the particles increased to a much greater extent than for TCR-SLN-1. After storage at $50{ }^{\circ} \mathrm{C}$ (Figure 4(F)), all particles had melted and merged, and the shape could not be determined. Therefore, through TEM imaging, it was confirmed that the surfactant played an important role in forming the shell to maintain the external shape of the particle; moreover, the properties of the internal solid lipid are also of significance to the maintenance of particle shape.

\section{In vitro release test of TCR-SLNs}

The in vitro drug release studies were performed by using modified Franz diffusion cells; in this study, modified Franz diffusion cells with a dialysis membrane with a pore size of $2.4 \mathrm{~nm}$ were used. The dialysis membrane retained the nanoparticles and allowed only the immediate transfer of the dissolved drug into the receiver compartment. The in vitro release test results for the prepared TCR-SLN-1 and TCR-SLN-2 formulations stored at three different temperatures are shown in Table 5. As the pore size of the membrane is $2.4 \mathrm{~nm}$, it is sufficiently small compared with the particle size to ensure that only free drug can be transferred to the receptor phase. The percentage of TCR released from TCR-SLN-1 and TCR-SLN-2 after $24 \mathrm{~h}$ was $22.52 \%$ and $20.11 \%$, respectively; there was no significant difference between these values. However, after storage at 


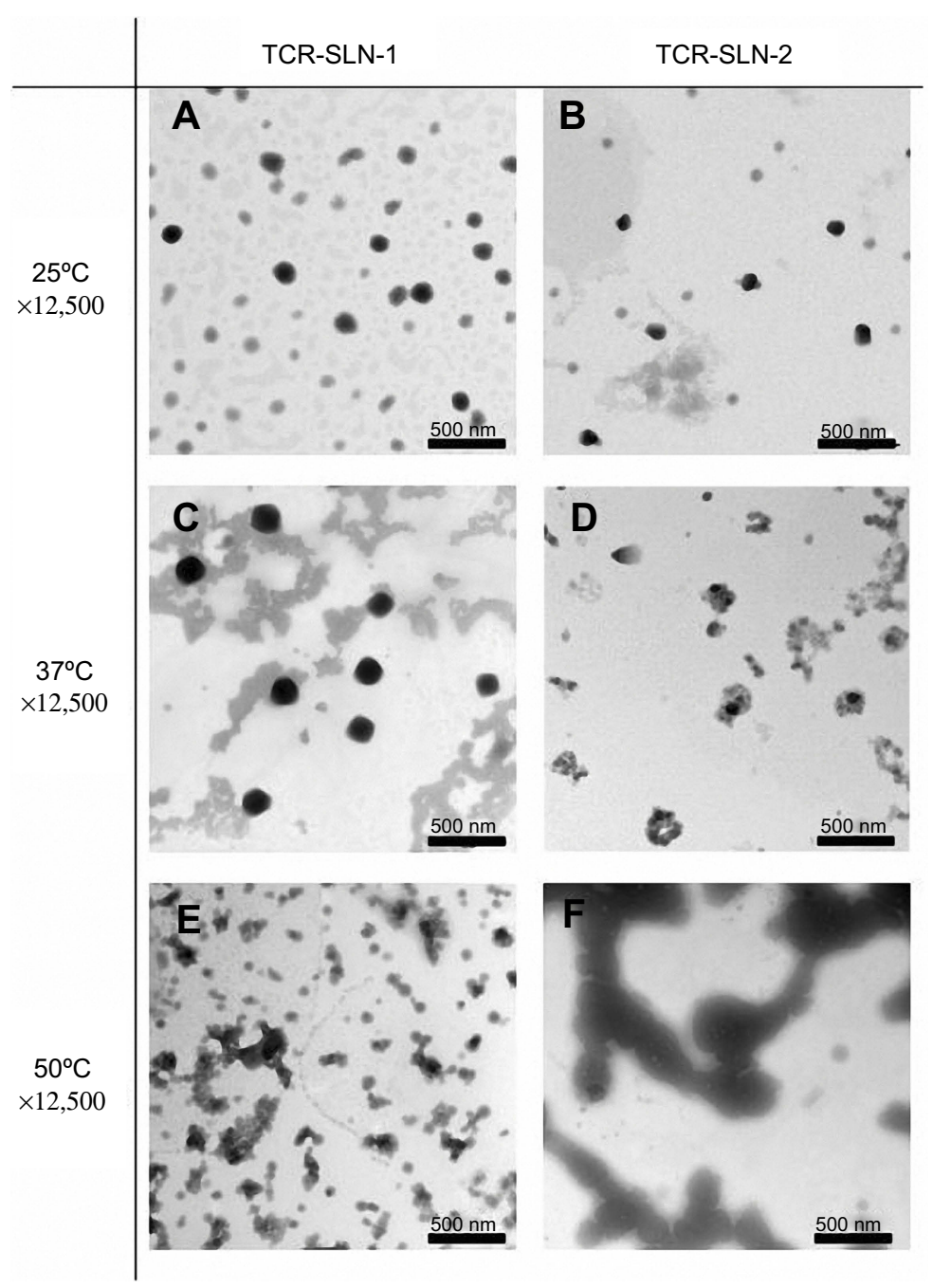

Figure 4 TEM images of TCR-SLNs dried at different temperatures (magnification: $\times 12,500$, scale bar $=500 \mathrm{~nm}$ ).

$37{ }^{\circ} \mathrm{C}$, TCR-SLN-2 displayed a significantly higher release than TCR-SLN-1, of approximately $37.80 \%$, because the particles were almost completely fragmented and did not retain their shape, allowing the TCR dispersed in the lipid to pass through the membrane. In contrast, TCR-SLN-1 stored at $37{ }^{\circ} \mathrm{C}$ demonstrated approximately $28 \%$ release, which was higher than the release rate from TCR-SLN-1 stored at $25{ }^{\circ} \mathrm{C}$, owing to lipid leakage, but constituted a smaller increase than that for TCR-SLN-2. The results correlated with the DSC and TEM results. In the TEM images after storage at $37{ }^{\circ} \mathrm{C}$, TCR-SLN-2 appeared more melted than TCRSLN-1. In addition, in the DSC thermogram, TCR-SLN1 exhibited a main melting peak of above $37{ }^{\circ} \mathrm{C}$, although there was a melting peak for cocoglyceride at approximately $28{ }^{\circ} \mathrm{C}$. However, TCR-SLN-2 exhibited a main melting peak before $37{ }^{\circ} \mathrm{C}$. The results of the in vitro test indicated that TCR-SLN-1 was more suitable for targeting the dermal layer: the outer skin temperature is $32{ }^{\circ} \mathrm{C}$, but the dermal temperature is $37{ }^{\circ} \mathrm{C}$; at this temperature, it is difficult for TCR-SLN-2 to maintain its shape. Furthermore, the amount released after storage of TCR-SLN-1 and TCR-SLN-2 at $50{ }^{\circ} \mathrm{C}$ was similar. High release percentages $(48.55 \%$ and $46.96 \%)$ were obtained after treatment at $50{ }^{\circ} \mathrm{C}$, because the morphology of the particles was not maintained and was completely destroyed, as shown in the TEM images. It was therefore confirmed that the state of the particles was dependent on temperature and greatly influenced the release rate. These thermodynamic differences are thought to have affected not only the morphology of the drug, but also the release rate. This also suggests the possibility of thermosensitive SLNs in which the particle maintains its morphology and penetrates as a nanoscale particle up to an outer skin temperature $\left(32^{\circ} \mathrm{C}\right)$, and then dissolves dermal temperature $\left(37^{\circ} \mathrm{C}\right)$. 
Table 5 Amount of TCR accumulated in $24 \mathrm{~h}$ in the in vitro and ex vivo test conducted at $37{ }^{\circ} \mathrm{C}$ on TCR-SLNs stored at different temperatures for $2 \mathrm{~h}$ (mean \pm standard error; ${ }^{*}$ Student's $t$-test, $p$-value $<0.05$ with TCR-SLN-2; **Student's $t$-test, $p$-value $<0.005$ with TCR-SLN-2)

\begin{tabular}{|l|l|l|l|l|}
\hline \multicolumn{2}{|l|}{} & \multicolumn{2}{|l|}{$\begin{array}{l}\text { Amount accumulated at } \mathbf{2 4} \mathbf{h} \text { after in vitro } \\
\text { release test }\end{array}$} & $\begin{array}{l}\text { Amount accumulated at } 24 \mathrm{~h} \text { after ex vivo skin } \\
\text { deposition test }\end{array}$ \\
\hline Storage temperature before test & TCR-SLN-I & TCR-SLN-2 & TCR-SLN-I & TCR-SLN-2 \\
\hline $25{ }^{\circ} \mathrm{C}$ & $22.52 \% \pm 1.17 \%$ & $20.11 \% \pm 0.82 \%$ & $21.82 \% \pm 4.38 \%$ & $8.31 \% \pm 1.26 \%$ \\
$37^{\circ} \mathrm{C}$ & $29.00 \% \pm 2.26 \% *$ & $37.80 \% \pm 2.08 \%$ & $16.89 \% \pm 1.45 \% * *$ & $3.80 \% \pm 0.58 \%$ \\
$50^{\circ} \mathrm{C}$ & $48.55 \% \pm 0.30 \%$ & $46.96 \% \pm 1.10 \%$ & $14.16 \% \pm 1.84 \% * *$ & $4.57 \% \pm 0.21 \%$ \\
\hline
\end{tabular}

\section{Ex vivo skin penetration test}

To assess the skin penetration of TCR from the prepared TCR-SLNs, the ability to permeate the skin was assessed ex vivo by using a Franz diffusion cell. The amount of TCR remaining in the excised rat dorsal skin after $24 \mathrm{~h}$ of the permeation test is shown in Table 5. The concentration of TCR-SLN-1 was 2.6 times higher than that of than TCRSLN-2 in the skin membrane, represented by the epidermis and dermis. This result indicated that although the external temperature of the Franz cells was $32{ }^{\circ} \mathrm{C}$, TCR-SLN-2 had already melted on the membrane and accumulated on the skin with difficulty through the stratum corneum layer, owing to the degraded particles. In contrast, TCR-SLN-1, which was not melted, as seen in the TEM images, was able to penetrate the epidermis and dermis as intact nanoparticles. In addition, TCR was not detected in the receptor phase of either TCR-SLNs after the $24 \mathrm{~h}$ permeation test, suggesting that the particles remain in the skin layer and not diffuse into the receptor phase. These properties are expected to be effective for targeting drug delivery to the skin and reducing side effects from systemic circulation. The results of the same experiment using the samples stored $2 \mathrm{~h}$ at $37^{\circ} \mathrm{C}$ and $50^{\circ} \mathrm{C}$ are shown in Table 5. As the temperature increased, TCRSLN-1 was unable to penetrate the skin, as the particles were already degraded; thus, the amount remaining on the membrane was relatively decreased. TCR-SLN-2 showed the same tendencies as TCR-SLN-1, but the difference was significant. For TCR-SLN-1 treatment at $50{ }^{\circ} \mathrm{C}$, the residual amount in the skin layer decreased as expected. In summary, TCR-SLNs could penetrate the stratum corneum owing to the maintained morphology of the particles; and, after penetration into the dermis, the TCR-SLNs remained in the dermis without transition to the receptor phase owing to their high lipophilicity and release at dermal temperature. This demonstrated that thermosensitive SLNs were suitable for skin-targeted drug delivery. SLNs with a small diameter allowed the improved penetration of nanoparticles into the skin and the controlled release of SLNs induce an increase in drug accumulation. ${ }^{56,57}$ In this study, permeation and penetration studies were also supported by previous analyses that focused on particle size. However, owing to the small particle size of our formulation, and the oil phase release temperature of the SLN, the amount remaining in a skin will increase. The slight difference between the average particle sizes of the TCR-SLNs formulations was not the key factor that influenced the drug penetration into the skin; it was the thermodynamic properties that resulted in release at a dermal temperature.

In this experiment, FT-IR imaging was used to confirm the depth of TCR penetration for each of the prepared TCRSLNs and the reference product by using the skin used in the Franz-diffusion test. The FT-IR spectrum was monitored at $3450 \mathrm{~cm}^{-1}$ as a wavelength specific for TCR. ${ }^{7}$ As shown in Figure 5, in the TCR-SLN-1, -2 , and the reference product, a very large amount of TCR was detected in the stratum corneum. Overall, for all groups, TCR appeared to remain in the stratum corneum. The results of FT-IR imaging through the skin for the reference product confirmed that a specific wavelength for TCR appeared broadly in the stratum corneum, but was hardly present in the epidermis. In comparison, the FT-IR images of prepared TCR-SLN-1 and TCR-SLN-2 showed TCR in deeper layers, up to $450 \mu \mathrm{m}$ depth, than the reference product. In addition, of the two TCR-SLNs, TCR-SLN-1 showed better permeability to deeper layers and a greater amount of penetrated TCR. Although a significant amount of TCR-SLN-1 penetrated up to $450 \mu \mathrm{m}$ in depth, TCR-SLN-2 penetration was found to be very low, even at $300 \mu \mathrm{m}$. These results confirmed the ex vivo skin penetration test results. In the skin permeation test, TCR-SLN-1 resulted in not only the greatest amount penetrated, but also penetrated deeper into the skin layer. In addition, the failure to pass through the receptor phase was a 


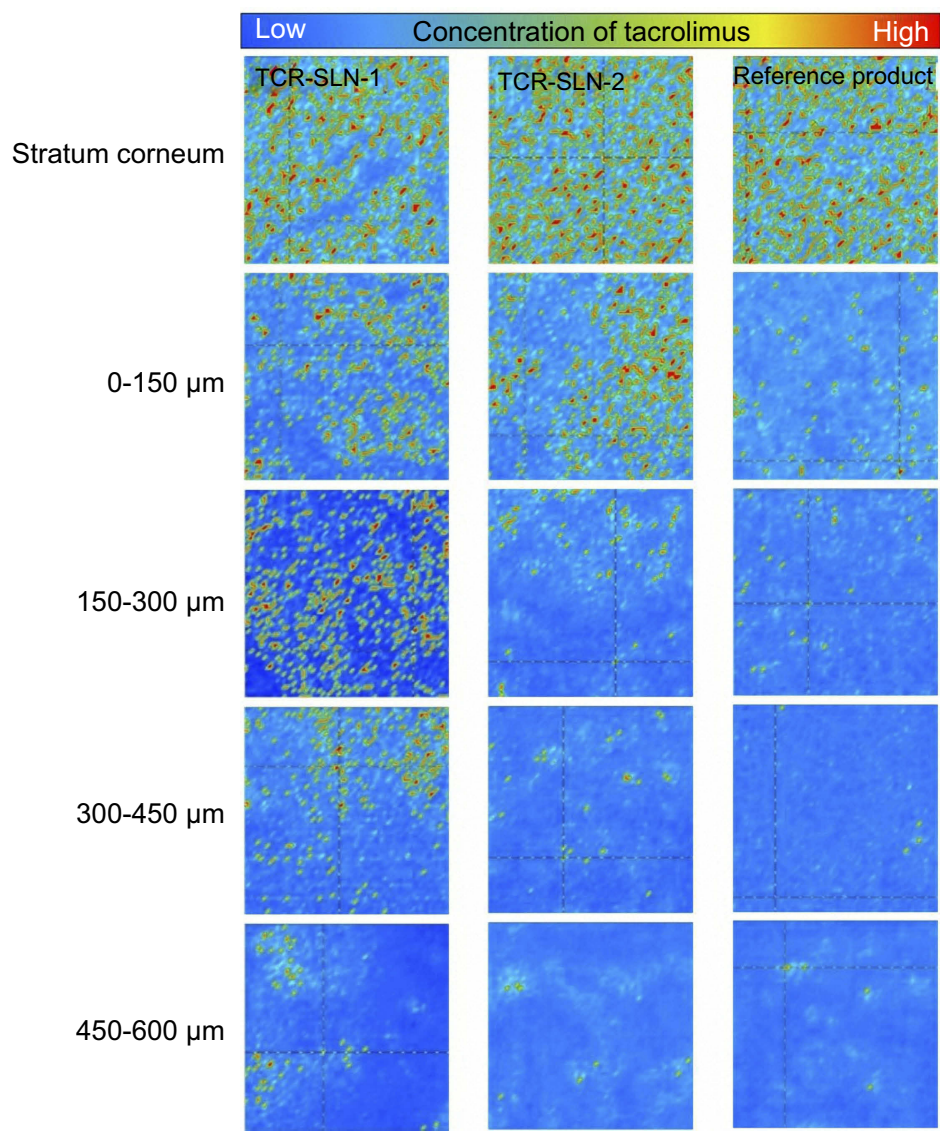

Figure 5 FT-IR imaging of the stratum corneum and skin at different depths after ex vivo skin penetration test at $37^{\circ} \mathrm{C}$ using the reference product and TCR-SLNs.

result of the formulation release at a dermal temperature, preventing penetration into the deeper layers of skin.

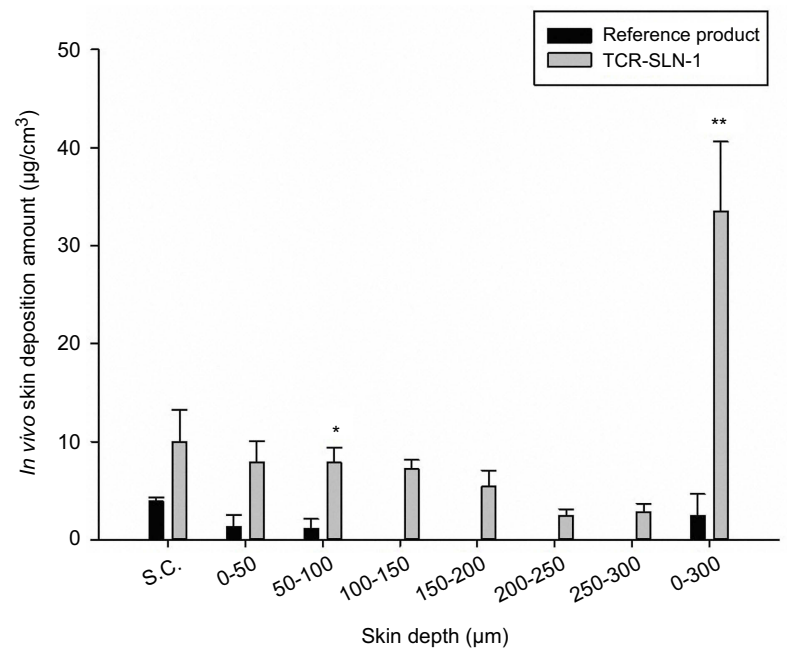

Figure 6 In vivo skin penetration test using reference product and TCR-SLN-I (mean \pm standard error; S.C.: stratum corneum, *Student's $t$-test, $p$-value $<0.05$ compared with the reference product; **Student's $t$-test, $p$-value $<0.01$ compared with the reference product).

\section{In vivo evaluation of TCR-SLNs In vivo skin penetration test of TCR-SLNs}

The residual amount of TCR in the skin, as determined by HPLC analysis of rabbit skin treated with TCR-SLN-1 and reference product once daily for 2 weeks, is shown in Figure 6. Overall, as observed in the ex vivo study, TCR-SLN-1 delivered more drug to deeper skin layers than the reference product. TCR-SLN-1 permeated from the stratum corneum to $300 \mu \mathrm{m}$ depth, and reference product was not detected from $150 \mu \mathrm{m}$ depth. The results were statistically significant at depths of 50-100 $\mu \mathrm{m}, 100$ $150 \mu \mathrm{m}$, and $0-300 \mu \mathrm{m}$. A large amount of TCR was detected at depths of $0-300 \mu \mathrm{m}$, indicating that TCRSLN-1 had penetrated deeper dermis layers. In addition, in the in vivo test results, penetration was greater than in the ex vivo tests. The drug appeared to accumulate after administration for 2 weeks. Plasma concentration was not measured, but it is expected that almost no migration to blood will occur, as shown by the ex vivo test.

The FT-IR imaging of TCR throughout the skin depth in the in vivo skin penetration study is shown in Figure 7. Similar to the ex vivo results, the highest intensities of 


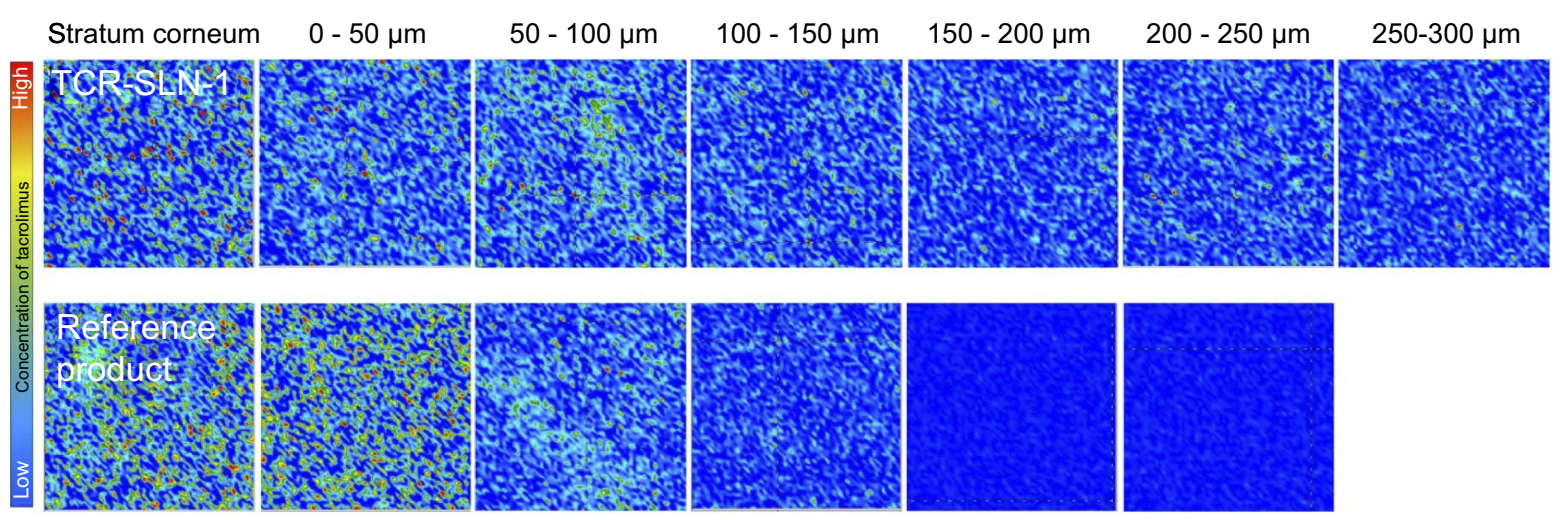

Figure 7 FT-IR imaging of the stratum corneum and skin at different depths after in vivo skin penetration test using the reference product and TCR-SLN-I.

TCR were found in the stratum corneum after administration of both the reference product and TCR-SLN-1, and gradually decreased as the skin deepened. For the reference product, TCR was not detectable below $150 \mu \mathrm{m}$. In contrast, TCR-SLN-1 was present in large quantities up to $300 \mu \mathrm{m}$ and was detected faintly at $500 \mu \mathrm{m}$ (data not shown). These results were highly correlated with the results in Figure 6 and FT-IR is considered to be able to detect even small amounts of TCR in deeper skin layers, as it directly detects TCR without the requirement for processes such as extraction or dilution. The results of the in vivo permeation test by skin depth using HPLC and FT-IR imaging were very similar, as were the ex vivo results. In addition, it was confirmed that TCRSLN-1 penetrated into the deep skin layers owing to its small size. The in vitro test results suggest that drug release would occur from the formulation remaining in the skin layer after penetration.

\section{Skin irritation test}

Skin irritation was assessed by the appearance of erythema and was assessed at $24 \mathrm{~h}$ after the final application. Five animals were assigned to each group, and nine were scored with a pre-classified score of $0-4$ (Table 3 ) from a blinded assessment of images of the skin. The score after reference product treatment was 2.7 , which suggested that the induced erythema was significantly more severe than that induced by TCR-SLN-1 (Score 1.2, Table 6). In Table 1,

Table 6 Skin irritation test of the reference product and TCRSLN-I (mean \pm standard error; **Student's $t$-test, $p$-value $<0.005$ compared with the reference product)

\begin{tabular}{|l|l|l|}
\hline & TCR-SLN-I & Reference product \\
\hline Score & $1.24 \pm 0.14 * *$ & $2.71 \pm 0.07$ \\
\hline
\end{tabular}

the image of each group before and after drug administration is shown. In each group, the rabbits that received the highest score and the lowest score for rabbit skin are presented. The skin treated with reference product displayed severe erythema; it is thought that the irritation occurs owing to the various excipients in the ointment. ${ }^{58,59}$ In contrast, the images after TCR-SLN-1 application to rabbit skin yielded no irritation. Even the skin with the highest score among the TCR-SLN-1 groups only displayed weak reddening.

\section{Conclusion}

These experimental results showed that TCR, a drug that cannot easily penetrate through the skin and has properties unsuitable for transdermal use, could be encapsulated in thermosensitive SLNs to produce relatively stable particles that accumulated in skin. It was confirmed that the surfactant in the shell of the particles affected the release properties. In general, the breaking point, at which a particle loses its shape, was dependent on the temperature of the surfactant: the lower the melting point of the surfactant, the greater the extent of degradation at low temperatures, even below room temperature. Among surfactants, two candidates were selected and their physicochemical properties were determined. The entrapment efficiency was $88 \%$, which showed that more TCR was present in the SLN than in the aqueous phase. In addition, DSC, $\mathrm{XRD}$, and FT-IR spectra showed that TCR was dispersed in the lipid inside the surfactant shell in an amorphous form. Finally, TEM was used to determine the morphology of prepared SLNs and the images were compared with DSC data to confirm that the appearance under different conditions was dependent on the temperature. Characterization of the TCRSLNs was performed by using an in vitro release test, an ex vivo skin penetration test, and FT-IR imaging. Two candidate formulations, TCR-SLN-1 and TCR-SLN-2, were produced 
and the release and skin penetration tests were performed for each candidate group at different temperatures. The release test showed significant differences in the prepared SLNs treated at $37^{\circ} \mathrm{C}$. This suggested that thermosensitive SLNs that released at a dermal temperature have been successfully manufactured. In addition, the skin penetration test showed a significant difference according to the treatment temperature of the sample, with a difference in the skin accumulation amount. These results suggested that thermosensitive SLNs prepared by using the thermodynamic properties that are dictated by the surfactant will provide enhanced drug delivery to the skin. An in vivo comparison of TCR-SLN-1 and the reference product was performed. The degree of skin penetration of TCR was evaluated by HPLC and FT-IR imaging methods. These two methods showed very similar results. Furthermore, similar to the ex vivo tests, TCR-SLN-1 permeated into a deeper layer.

In conclusion, thermosensitive SLNs with different thermodynamic properties, dictated by the type of surfactant forming the shell, are very effective for topical drug delivery. This effect was confirmed in ex vivo and in vivo tests and was visualized by using FT-IR imaging.

\section{Acknowledgments}

This study was supported by National Research Foundation of Korea Grant funded by the Korea government (NRF2018R1A1A1A05023012, NRF-2018R1D1A1B07050538, and 2017R1A5A2015541).

\section{Disclosure}

The authors declare that they have no conflicts of interest in this work.

\section{References}

1. Chang K-T, Lin -HY-H, Kuo C-H, Hung C-H. Tacrolimus suppresses atopic dermatitis-associated cytokines and chemokines in monocytes. $J$ Microbiol Immunol Infect. 2016;49:409-416. doi:10.1016/j. jmii.2014.07.006

2. Zhang D, Pan X, Wang S, et al. Multifunctional poly (methyl vinyl etherco-maleic anhydride)-graft-hydroxypropyl- $\beta$-cyclodextrin amphiphilic copolymer as an oral high-performance delivery carrier of tacrolimus. Mol Pharm. 2015;12:2337-2351. doi:10.1021/acs.molpharmaceut.5b0 0010

3. Goebel AS, Neubert RH, Wohlrab J. Dermal targeting of tacrolimus using colloidal carrier systems. Int J Pharm. 2011;404:159-168. doi:10.1016/j.ijpharm.2010.11.029

4. Lei W, Yu C, Lin H, Zhou X. Development of tacrolimus-loaded transfersomes for deeper skin penetration enhancement and therapeutic effect improvement in vivo. Asian J Pharma Sci. 2013;8:336-345. doi:10.1016/j.ajps.2013.09.005
5. Lapteva M, Mondon K, Möller M, Gurny R, Kalia YN. Polymeric micelle nanocarriers for the cutaneous delivery of tacrolimus: a targeted approach for the treatment of psoriasis. Mol Pharm. 2014;11:2989-3001. doi:10.1021/mp400639e

6. Shin S-B, Cho H-Y, Kim D-D, Choi H-G, Lee Y-B. Preparation and evaluation of tacrolimus-loaded nanoparticles for lymphatic delivery. Eur J Pharm Biopharm. 2010;74:164-171. doi:10.1016/j.ejpb.2009.08.006

7. Pople PV, Singh KK. Development and evaluation of colloidal modified nanolipid carrier: application to topical delivery of tacrolimus. Eur $J$ Pharm Biopharm. 2011;79:82-94. doi:10.1016/j.ejpb.2011.02.016

8. Desfrançois C, Auzély R, Texier I. Lipid nanoparticles and their hydrogel composites for drug delivery: A review. Pharmaceuticals. 2018;11:118-145. doi:10.3390/ph11040118

9. Aljaeid BM, Hosny KM. Miconazole-loaded solid lipid nanoparticles: formulation and evaluation of a novel formula with high bioavailability and antifungal activity. Int J Nanomedicine. 2016;11:441447. doi:10.2147/IJN.S100625

10. Liu B, Han L, Liu J, Han S, Chen Z, Jiang L. Co-delivery of paclitaxel and TOS-cisplatin via TAT-targeted solid lipid nanoparticles with synergistic antitumor activity against cervical cancer. Int $J$ Nanomedicine. 2017;12:955-968. doi:10.2147/IJN.S115136

11. Kumar R, Singh A, Garg N, Siril PF. Solid lipid nanoparticles for the controlled delivery of poorly water soluble non-steroidal anti-inflammatory drugs. Ultrason Sonochem. 2018;40:686-696. doi:10.1016/j. ultsonch.2017.08.018

12. Rupenagunta A, Somasundaram I, Ravichandiram V, Kausalya J, Senthilnathan B. Solid lipid nanoparticles-A versatile carrier system. J Pharma Res. 2011;4:2069-2075.

13. Zoubari G, Staufenbiel S, Volz P, Alexiev U, Bodmeier R. Effect of drug solubility and lipid carrier on drug release from lipid nanoparticles for dermal delivery. Eur J Pharm Biopharm. 2017;110:39-46. doi:10.1016/j.ejpb.2016.10.021

14. Ud Din F, Aman W, Ullah I, et al. Effective use of nanocarriers as drug delivery systems for the treatment of selected tumors. Int $J$ Nanomedicine. 2017;12:7291-7309. doi:10.2147/IJN.S146315

15. Choi YH, Han H-K. Nanomedicines: current status and future perspectives in aspect of drug delivery and pharmacokinetics. $J$ Pharm Investig. 2018;48:43-60. doi:10.1007/s40005-017-0370-4

16. Saporito F, Sandri G, Bonferoni MC, et al. Essential oil-loaded lipid nanoparticles for wound healing. Int J Nanomedicine. 2018;13:175186. doi:10.2147/IJN.S152529

17. Lohan SB, Bauersachs S, Ahlberg S, et al. Ultra-small lipid nanoparticles promote the penetration of coenzyme Q10 in skin cells and counteract oxidative stress. Eur J Pharm Biopharm. 2015;89:201207. doi:10.1016/j.ejpb.2014.12.008

18. Oliveira MS, Mussi SV, Gomes DA, et al. $\alpha$-Tocopherol succinate improves encapsulation and anticancer activity of doxorubicin loaded in solid lipid nanoparticles. Colloid Surf B Biointerfaces. 2016;140:246-253. doi:10.1016/j.colsurfb.2015.12.019

19. Ding Y, Pyo S, Müller R. smartLipids ${ }^{\circledR}$ as third solid lipid nanoparticle generation-stabilization of retinol for dermal application. Die Pharmazie Int J Pharma Sci. 2017;72:728-735.

20. Schäfer-Korting M, Mehnert W, Korting H-C. Lipid nanoparticles for improved topical application of drugs for skin diseases. Adv Drug Deliv Rev. 2007;59:427-443. doi:10.1016/j.addr.2007.04.006

21. Dabbagh A, Abdullah BJJ, Abu Kasim NH, Abdullah H, Hamdi M. A new mechanism of thermal sensitivity for rapid drug release and low systemic toxicity in hyperthermia and thermal ablation temperature ranges. Int $J$ Hyperthermia. 2015;31:375-385. doi:10.3109/ 02656736.2015.1006268

22. Cha JM, You DG, Choi EJ, et al. Improvement of antitumor efficacy by combination of thermosensitive liposome with high-intensity focused ultrasound. J Biomed Nanotechnol. 2016;12:1724-1733. doi:10.1166/jbn.2016.2272 
23. Sarwal A, Singh G, Singh S, Singh K, Sinha V. Novel and effectual delivery of an antifungal agent for the treatment of persistent vulvovaginal candidiasis. $J$ Pharm Investig. 2019;49:135-147. doi: 10.1007/s40005-018-0395-3

24. Centelles MN, Wright M, So P-W, et al. Image-guided thermosensitive liposomes for focused ultrasound drug delivery: using NIRF-labelled lipids and topotecan to visualise the effects of hyperthermia in tumours. J Control Release. 2018;280:87-98. doi:10.1016/j.jconrel.2018.04.047

25. Guo Y, Zhang Y, Ma J, et al. Light/magnetic hyperthermia triggered drug released from multi-functional thermo-sensitive magnetoliposomes for precise cancer synergetic theranostics. $J$ Control Release. 2018;272:145-158. doi:10.1016/j.jconrel.2017.04.028

26. Park SM, Kim MS, Park S-J, et al. Novel temperature-triggered liposome with high stability: formulation, in vitro evaluation, and in vivo study combined with high-intensity focused ultrasound (HIFU). $J$ Control Release. 2013;170:373-379. doi:10.1016/j.jconrel.2013.06.003

27. Kim YT, Ma D, Sim JK, Kim S-H. Simultaneous evaluation of thermal and non-thermal effects of high-intensity focused ultrasound on a tissue-mimicking phantom. Ultrasound Med Biol. 2018;44:1799-1809. doi:10.1016/j.ultrasmedbio.2018.03.024

28. Tagami T, Foltz WD, Ernsting MJ, et al. MRI monitoring of intratumoral drug delivery and prediction of the therapeutic effect with a multifunctional thermosensitive liposome. Biomaterials. 2011;32:6570-6578. doi:10.1016/j.biomaterials.2011.05.029

29. Kim HR, You DG, Park S-J, et al. MRI monitoring of tumor-selective anticancer drug delivery with stable thermosensitive liposomes triggered by high-intensity focused ultrasound. Mol Pharm. 2016;13:1528-1539. doi:10.1021/acs.molpharmaceut.6b00013

30. Maniyar MG, Kokare CR. Formulation and evaluation of spray dried liposomes of lopinavir for topical application. $J$ Pharm Investig. 2019;49:259-270. doi:10.1007/s40005-018-0403-7

31. Im GJ, Chae SY, Lee KC, Lee DS. Controlled release of insulin from $\mathrm{pH} /$ temperature-sensitive injectable pentablock copolymer hydrogel. Journal of Controlled Release. 2009;137:20-24. doi:10.1016/j. jconrel.2009.02.021

32. Trotta M, Debernardi F, Caputo O. Preparation of solid lipid nanoparticles by a solvent emulsification-diffusion technique. Int $J$ Pharm. 2003;257:153-160.

33. Praça FSG, Medina WSG, Eloy JO, et al. Evaluation of critical parameters for in vitro skin permeation and penetration studies using animal skin models. Eur J Pharm Sci. 2018;111:121-132. doi:10.1016/j.ejps.2017.09.034

34. Rubins A, Gutmane R, Valdmane N, Stevenson P, Foster C, Undre N. Pharmacokinetics of $0.1 \%$ tacrolimus ointment after first and repeated application to adults with moderate to severe atopic dermatitis. J Invest Dermatol. 2005;125:68-71. doi:10.1111/j.0022-202X.2005.23754.x

35. Park C-W, Kim J-Y, Rhee Y-S, et al. Preparation and valuation of a topical solution containing eutectic mixture of itraconazole and phenol. Arch Pharm Res. 2012;35:1935-1943. doi:10.1007/s12272-012-1110-y

36. Xie S, Zhu L, Dong Z, et al. Preparation, characterization and pharmacokinetics of enrofloxacin-loaded solid lipid nanoparticles: influences of fatty acids. Colloid Surf $B$ Biointerfaces. 2011;83:382-387. doi:10.1016/j.colsurfb.2010.12.014

37. Wang R, Li L, Wang B, Zhang T, Sun L. FK506-loaded solid lipid nanoparticles: preparation, characterization and in vitro transdermal drug delivery. Afr J Pharm Pharmacol. 2012;6:904-913.

38. Kalepu S, Nekkanti V. Insoluble drug delivery strategies: review of recent advances and business prospects. Acta Pharm Sin B. 2015;5:442-453. doi:10.1016/j.apsb.2015.07.003

39. Pople PV, Singh KK. Targeting tacrolimus to deeper layers of skin with improved safety for treatment of atopic dermatitis. Int J Pharm. 2010;398:165-178. doi:10.1016/j.ijpharm.2010.07.008

40. Jain S, Addan R, Kushwah V, Harde H, Mahajan RR. Comparative assessment of efficacy and safety potential of multifarious lipid based Tacrolimus loaded nanoformulations. Int J Pharm. 2019;562:96-104. doi:10.1016/j.ijpharm.2019.03.042
41. Kim K-T, Lee HS, Lee J-J, et al. Nanodelivery systems for overcoming limited transportation of therapeutic molecules through the blood-brain barrier. Future Med Chem. 2018;10:2659-2674. doi:10.4155/fmc-2018-0208

42. Freitas C, Müller R. Correlation between long-term stability of solid lipid nanoparticles (SLN ${ }^{\mathrm{TM}}$ ) and crystallinity of the lipid phase. Eur $J$ Pharm Biopharm. 1999;47:125-132.

43. Jawahar N, Baruah UK, Singh V. Co-delivery of chloroquine phosphate and azithromycin nanoparticles to overcome drug resistance in malaria through intracellular targeting. J Pharma Sci Res. 2019;11:33-40.

44. Pathak P, Nagarsenker M. Formulation and evaluation of lidocaine lipid nanosystems for dermal delivery. AAPS PharmSciTech. 2009;10:985-992. doi:10.1208/s12249-009-9287-1

45. Corrigan DO, Healy AM, Corrigan OI. The effect of spray drying solutions of bendroflumethiazide/polyethylene glycol on the physicochemical properties of the resultant materials. Int $J$ Pharm. 2003;262:125-137.

46. Oh D-W, Kang J-H, Lee H-J, et al. Formulation and in vitro/in vivo evaluation of chitosan-based film forming gel containing ketoprofen. Drug Deliv. 2017;24:1056-1066. doi:10.1080/10717544.2017.1346001

47. Lee H-J, Kang J-H, Lee H-G, et al. Preparation and physicochemical characterization of spray-dried and jet-milled microparticles containing bosentan hydrate for dry powder inhalation aerosols. Drug Des Devel Ther. 2016;10:4017-4030. doi:10.2147/DDDT.S120356

48. Pople PV, Singh KK. Development and evaluation of colloidal modified nanolipid carrier: application to topical delivery of tacrolimus, Part II-in vivo assessment, drug targeting, efficacy, and safety in treatment for atopic dermatitis. Eur $J$ Pharm Biopharm. 2013;84:72-83. doi:10.1016/j.ejpb.2012.11.026

49. Park C-W, Lee H-J, Oh D-W, Kang J-H, Han C-S, Kim D-W. Preparation and in vitro/in vivo evaluation of PLGA microspheres containing norquetiapine for long-acting injection. Drug Des Devel Ther. 2018;12:711-719. doi:10.2147/DDDT.S151437

50. Lee G-S, Lee D-H, Kang K-C, Lee C-I, Pyo H-B, Choi T-B. Preparation and characterization of bis-ethylhexyloxyphenolmethoxyphenyltriazine (BEMT) loaded solid lipid nano-particles (SLN). $J$ Ind Eng Chem. 2007;13:1180-1187.

51. Din F, Choi JY, Kim DW, et al. Irinotecan-encapsulated doublereverse thermosensitive nanocarrier system for rectal administration. Drug Deliv. 2017;24:502-510. doi:10.1080/10717544.2016.1272651

52. Park JH, Kim DS, Mustapha O, et al. Comparison of a revaprazanloaded solid dispersion, solid SNEDDS and inclusion compound: physicochemical characterisation and pharmacokinetics. Colloid Surf B Biointerfaces. 2018;162:420-426. doi:10.1016/j. colsurfb.2017.12.017

53. Ud Din F, Mustapha O, Kim DW, et al. Novel dual-reverse thermosensitive solid lipid nanoparticle-loaded hydrogel for rectal administration of flurbiprofen with improved bioavailability and reduced initial burst effect. Eur J Pharm Biopharm. 2015;94:64-72. doi:10.1016/j.ejpb.2015.04.019

54. Jeong SC, Kim DS, Jin SG, et al. Development of a novel celecoxibloaded nanosuspension using a wet media milling process. Die Pharmazie Int J Pharma Sci. 2018;73:498-502.

55. Urbán-Morlán Z, Ganem-Rondero A, Melgoza-Contreras LM, Escobar-Chávez JJ, Nava-Arzaluz MG, Quintanar-Guerrero D. Preparation and characterization of solid lipid nanoparticles containing cyclosporine by the emulsification-diffusion method. Int $J$ Nanomedicine. 2010;5:611-620. doi:10.2147/IJN.S12125

56. Garcês A, Amaral M, Lobo JS, Silva A. Formulations based on solid lipid nanoparticles (SLN) and nanostructured lipid carriers (NLC) for cutaneous use: A review. Eur J Pharm Sci. 2018;112:159-167. doi:10.1016/j.ejps.2017.11.023

57. El-Housiny S, Shams Eldeen MA, El-Attar YA, et al. Fluconazoleloaded solid lipid nanoparticles topical gel for treatment of pityriasis versicolor: formulation and clinical study. Drug Deliv. 2018;25:7890. doi:10.1080/10717544.2017.1413444 
58. Hansen L, Lange R, Gupta S. Development and evaluation of a guideline for monitoring propylene glycol toxicity in pediatric intensive care unit patients receiving continuous infusion lorazepam. J Pediatr Pharmacol Ther. 2015;20:367-372. doi:10.5863/1551-6776-20.5.367
59. Petry T, Bury D, Fautz R, et al. Review of data on the dermal penetration of mineral oils and waxes used in cosmetic applications. Toxicol Lett. 2017;280:70-78. doi:10.1016/j.toxlet.2017. 07.899 


\section{Supplementary materials}

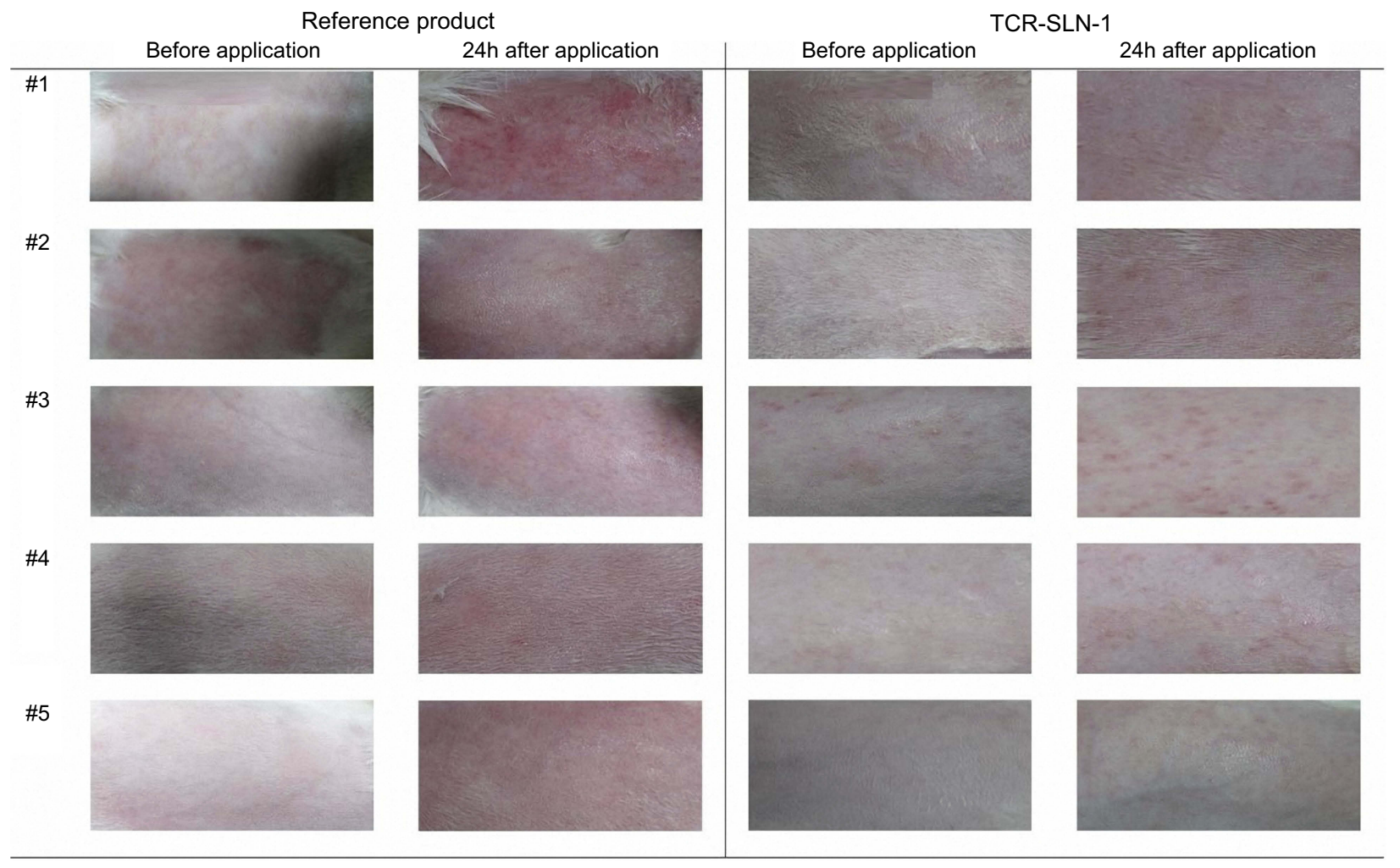

Figure SI Images of skin samples from each group (24h after drug application).

\section{Publish your work in this journal}

The International Journal of Nanomedicine is an international, peerreviewed journal focusing on the application of nanotechnology in diagnostics, therapeutics, and drug delivery systems throughout the biomedical field. This journal is indexed on PubMed Central, MedLine, CAS, SciSearch ${ }^{\mathbb{B}}$, Current Contents ${ }^{\mathbb{B}} /$ Clinical Medicine,
Journal Citation Reports/Science Edition, EMBase, Scopus and the Elsevier Bibliographic databases. The manuscript management system is completely online and includes a very quick and fair peer-review system, which is all easy to use. Visit http://www.dovepress.com/ testimonials.php to read real quotes from published authors. 